\title{
PROCEDURE FOR THE IMPLEMENTATION OF AUTONOMOUS MOBILE ROBOTS ON THE CONSTRUCTION SITE
}

\author{
Prof. Dr.-Ing. / Univ. Tokio Thomas Bock \\ Dipl.-Ing. Klaus Kreupl \\ Technical University of Munich \\ Chair of Building Realization and Informatics \\ Arcisstrasse 21, D-80333 Muenchen, Germany \\ klaus.kreupl@bri.ar.tum.de
}

\begin{abstract}
The implementation of industrial robots in construction industry has proven to be difficult. The problem is not the technique but rather the difficulties in mixing human and robot labour in the dynamic, unstructured environment on site. Both systems need their specific basic conditions, which are impossible to provide on the construction site at the same time.

Now, on account of this, a new procedure for an extensively automated interior finishing work should be described:

Based on a recently developed autonomous mobile robot for drilling and mounting in concrete ceilings, a family of robots was identified to provide at least 80 percent of interior works: Three working units, which are modular designed, have different purposes: 1.Transport the elements from the remote store to the place of assembly. 2.Drill and prepare connections in the building shell. 3.Position and assemble the prefabricated buildingelements.

An appropriate procedure was described and simulated by the example of an office building construction. Calculations were compared with conventional building methods to estimate the system's effectiveness.
\end{abstract}

KEYWORDS: Assembly Robots, (On Site-) Automation, Autonomous, Man/Machine Systems, Process Automation, Simulation

\section{INTRODUCTION}

A high degree of automation and integration of different production levels has already been achieved in industrial manufacturing by the application of microelectronics and intelligent control systems. In the construction industry, however, this development is so far limited to computer aided planning (e.g. Computer aided architectural design, 3D modelling, calculation of costs and quantities, preparation of project specifications for contract award, structural calculations, etc.). Industrial automated processes are only implemented in the production of components in stationary prefabrication plants (e.g. masonry and concrete elements) in order to obtain high-quality results [3].
But there is a high demand for such solutions: The Institute for Social Research estimates an additional market in Germany of approx. 1.2 million individuals willing to invest in residential housing if the object costs were reduced from currently 250,000 Euros down to about 150,000 Euros. Of course the enormously high plot prices contribute to this situation, but construction costs alone still have a share of approx. $50 \%$ of the total costs. Hence strategies within this area need to be developed.

First of all the value adding processes should be transferred from the building site into the fabrication plant: The continuing development of modular and prefabricated systems has a strong impact here.

The conventional building construction on site represents the largest potentials for cost and time reduc- 
tions as well as potentials for new technologies in the area of automation.

Irregular demand, great variety and high capital costs in construction require similar strategies as already applied in the manufacturing industry. The shorter the time span between contract signing and utilization of the building the cheaper the financing of the project. As a result robot oriented manufacturing requires standardized planning, production and assembly systems [1].

Systems for these applications have been developed for several years, but they have not yet become generally accepted on the market.

\section{GENERAL METHODS FOR AUTO- MATIC ASSEMBLY OF INTERIOR ELE- MENTS}

A look at many different existing approaches of assembly processes on-site shows two general procedures:

\subsection{Assembly from Outside and Vertically}

In this method all construction elements (both structural and light interior systems) are brought in by crane or gantry crane systems from outside and above. The whole working area has to be protected by some kind of roofing during the construction period, because interior building elements are susceptible to weather influences.

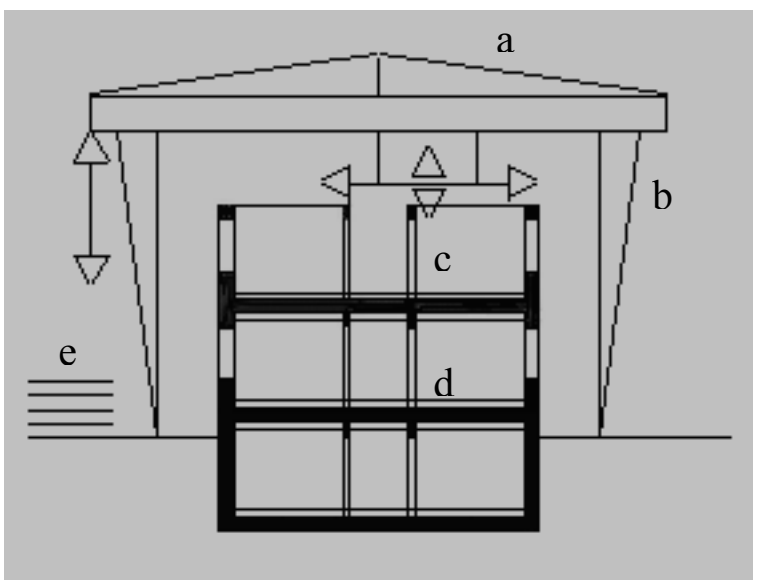

Legend:
a) temporary roofage
b) (gantry) crane system
c) level in assembly
d) level(s) already assembled
e) bin location

Figure 1. Assembly from outside/vertical, cross section
The advantage of this method is the possibility to handle heavy and big building elements. Gantry crane systems are able to provide a high degree of positioning precision.

On the other hand this technology needs high investment costs, what means that it will be used only in huge projects by large companies.

\subsection{Assembly from Inside and Horizontally}

This method of automatic assembly is much closer to common procedures on-site. At first the shell is produced (no matter whether in a common or in a more advanced way with prefabricated structural elements). After finishing the curtain wall and the roofing, the horizontal assembly of interior elements with small and light units can be done.

The disadvantage of this technique is that the shell determines weights and dimensions of all working systems. In consequence the prefabricated elements have to be divided into smaller units. Their handling and positioning is more complicated and, hence there is a high demand on organisation and logistics on site. Consequently this leads to a high complexity of all assembly systems.

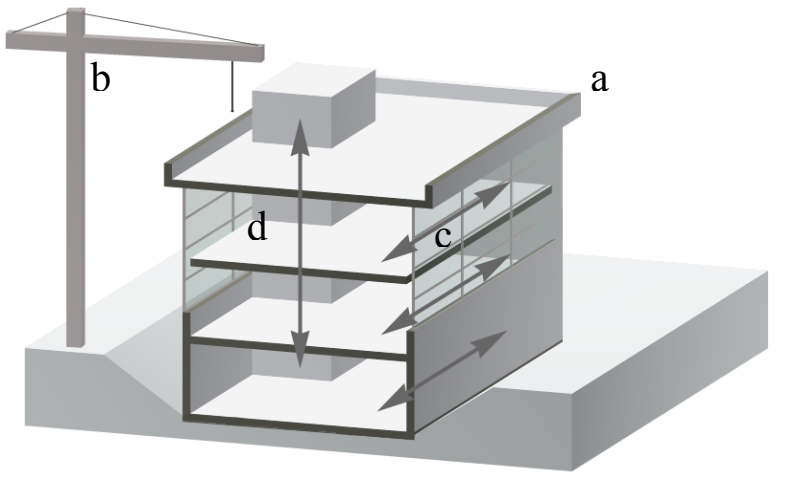

Legend:

a) building shell, rain proofing

b) crane system (shell construction)

c) Horizontal transport of elements and horizontal direction of assembly

d) elevator for vertical transport of robots and building elements

Figure 2. Assembly from inside/horizontal

On the other hand this procedure is much closer to common organisation structures on site. In addition it can be used by several contractors and requires a lower financial investment. That is why the implementation of systems, based on this second method will be more likely in the near future. 


\section{MOBILE AND AUTONOMOUS RO- BOT FOR DRILLING AND FIXING}

In the context of a research project, engineers from the university of Erlangen- Nürnberg and Baumann $\mathrm{GmbH}$ developed a robot for drilling and mounting attachments to concrete ceiling slabs. The substantial characteristics are:

The processing unit for ceiling attachment is mounted on a transportation unit.

"It was decided to use a track vehicle as transportation module because of the multitude of obstacles on the floor. Navigation is realized by an image processing system mounted on the transportation module detecting a chalk line, which had been applied manually on the floor. So the machine is able to follow the line and to detect the marked points of operation. As soon as an operating point arrives in the camera's field of vision, the vehicle is slowing down and stops. Then the deviation into $\mathrm{x}$ and $\mathrm{y}$ direction is determined. Additionally the inclination of the vehicle is measured and the deviation of the tool axle due to it is calculated. By NC-axles in $\mathrm{x}$ and $\mathrm{y}$ direction these deviations are corrected ".[4]

The travel on-site and the change from one chalk line to another is controlled by a joystick. At the point of operation the process module drills the hole into the concrete ceiling, subsequently fixes a pin or a dowel and assembles the suspension rod for a suspended ceiling system.

In order to perform these tasks the prototype comprises of several lifting mechanisms, a conventional hammer drill, and a conventional device for fixing bolts. Sensor technology and computer control ensure the fine positioning and the perpendicular transfer of the point of operation from the soil to the ceiling [2].

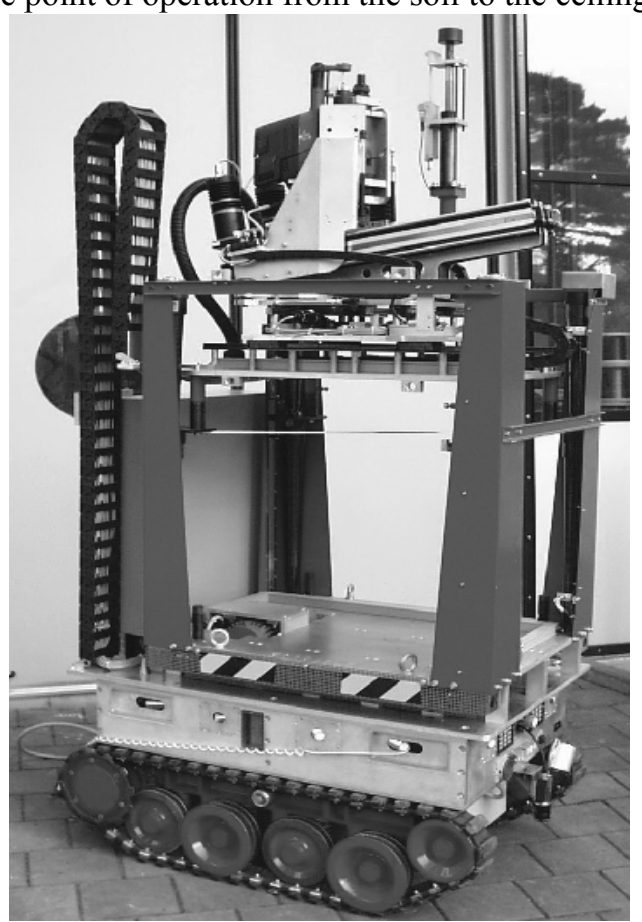

Figure 3. Prototype of a mobile robot system
On-site tests of the robot revealed several obstacles for an efficient application in common project organisation: First of all the problems of mixing human and robot labour in an inconstant, indefinite environment became evident. Both systems require their specific basic conditions, which can not be provided on the construction site together.

Now, on account of this, a new process for an extensively automated interior finishing work needed to be designed. The degree of automation in interior assembly should be increased to approximately $80 \%$.

\section{MODULAR ROBOT SYSTEM FOR INTERIOR ASSEMBLY ON-SITE}

The decision from an early state of the project to design the prototype as a modular system, were now proved to be right. The flexible carrier unit, is able to transport alternative processing modules for different assembly operations.

Three modules were identified to be necessary and sufficient to provide the aspired high degree of automation:

$\begin{array}{lc}\text { module 1 } & \text { module 2 } \\ \text { drilling \& } & \text { transport of } \\ \text { mounting } & \text { elements }\end{array}$

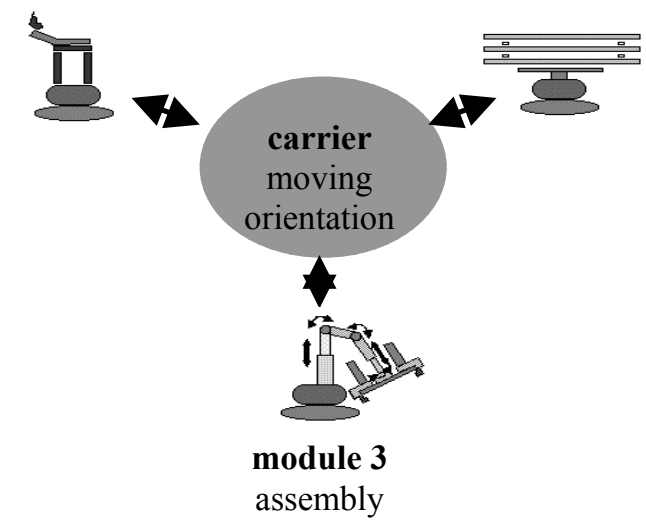

Figure 4. Robot family for a complete interior work on-site

The processing modules perform different tasks: 1.Transport the building elements from remote store to the place of assembly. 2.Drill holes and prepare connections in the building shell. 3.Position and assemble the prefabricated building elements. 


\section{EXTENSIVE ROBOTIC INTERIOR ASSEMBLY ON-SITE}

\section{1. $\quad$ Procedure Design}

The scenario of the construction of an office building was chosen to develop a procedure for extensive robotic interior assembly on-site.

This application was selected because today it already provides a high level of standards in processes and building systems. In addition to that, there is a high average rate of tenant changes, therefore an often need for reconstruction (every 5-8 years). A technology which considerably shortens on-site construction time in reconstruction is most effective because it minimises losses of rent.

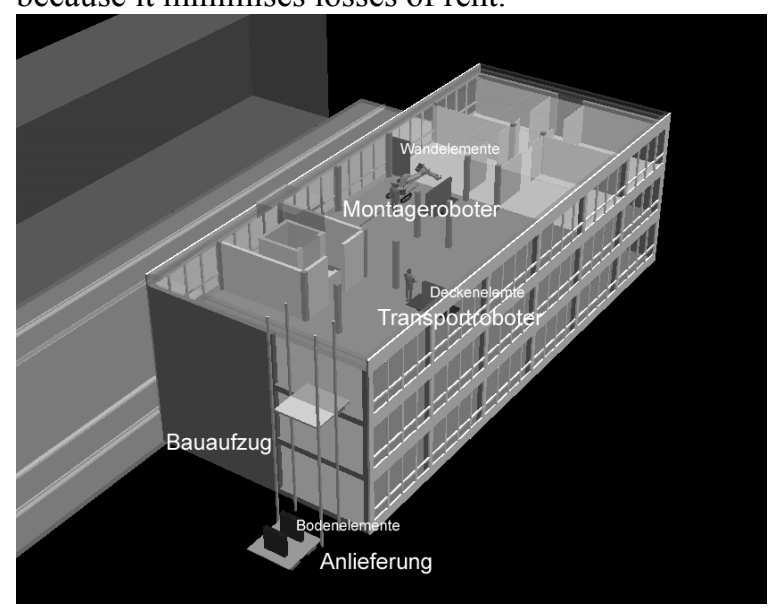

Figure 5. Simulation: "interior robots in office building"; overview

The procedure begins with the mounting robot's work (as described before). It has to prepare all attachments for interior fittings in the hard concrete shell. Afterwards an (external or internal) elevator is allowed to begin with the transport of prefabricated building elements from a remote storage area to the floor of assembly. This elevator also relocates the robots from one level to the other.

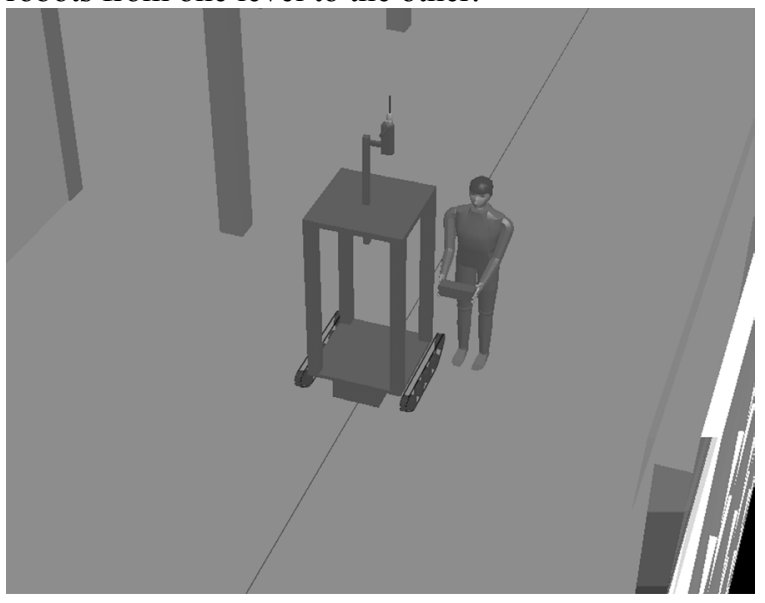

Figure 6. Simulation: "interior robots in office building"; mounting unit

A platform transfers the elements to the transportation unit, which takes over the horizontal transport under manual control. In addition to the carrier this device consists of a turnable and tiltable platform as processing module.

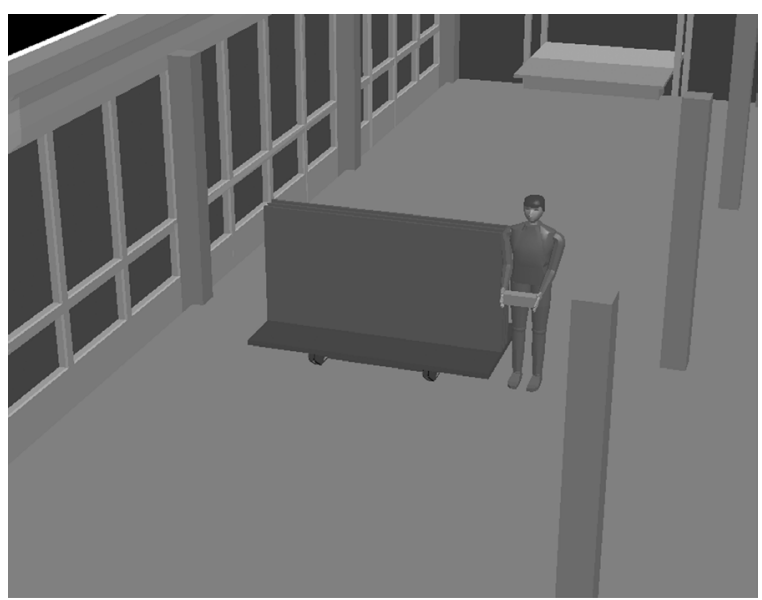

Figure 7. Simulation "interior robots in office building", transport unit

Through a second transfer table the elements are handed over to the assembly device.

This unit is vital for the new procedure: It has to take over the different elements like ceiling panels, walls or floor plates with a vacuum gripper. After that the robot does the fine positioning and fixing of each element.

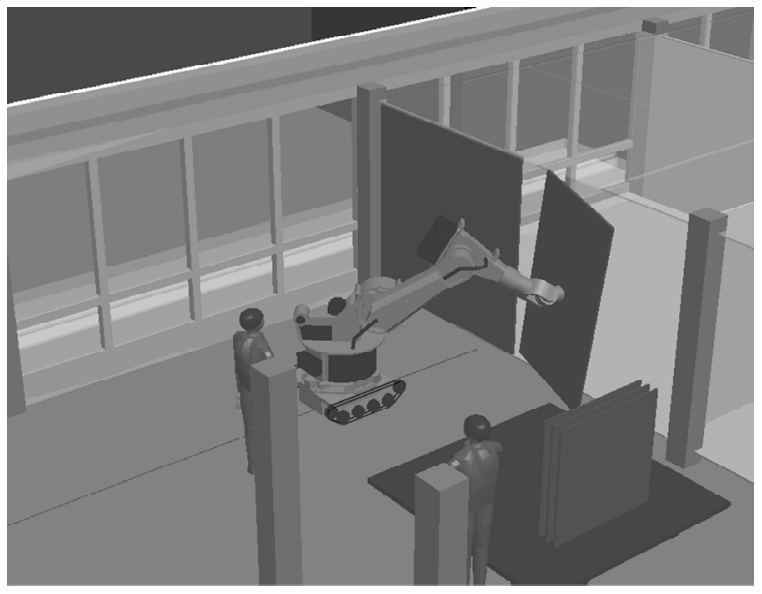

Figure 8. Simulation: "interior robots in office building"; assembly unit 


\subsection{Robot Design}

A special task is to balance the weight of building elements and the lifting capacity of the robot with the weight of the machine, because it is necessary not to increase the common load capacity of the ceiling construction. It will be essential to develop a special lightweight unit. Common industrial robots are not capable to achieve this. Due to the low positioning accuracy of the vehicle, fine location detection is required, which takes a long time. In order to be more efficient it is necessary to provide an ample work envelope which allows to assemble several elements from one position. The simulation showed that it is well possible to assemble three ceiling and three floor elements up to the size of $1250 \mathrm{~mm}$ to $600 \mathrm{~mm}$ and three wall plates with a width of $1250 \mathrm{~m}$ and a height of $3500 \mathrm{~mm}$.

It is also necessary to develop a system of interior building elements which is adequate to the automated assembly. In addition its parts have to be flexible and reusable. The focus has to be on how to produce them tailor made and customer driven while costeffective. The level of prefabrication is vital for the degree of the rationalisation these building elements can reach.

For the scenario a catalogue of necessary building elements, respecting all functional needs and modular ordered was defined. The elements were prepared to fit into a later robot oriented design (ROD).

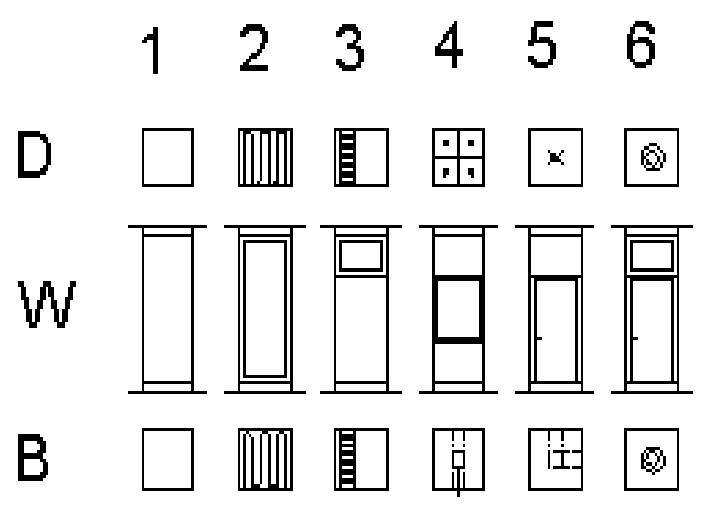

Legend:

$\mathrm{D}=$ Ceiling elements 1 : surface only, different materials; 2: heating and cooling elements; 3: Element with different lights 4 : Lightning ceiling 5: elements with installations e.g. sprinklers 6: ventilation element. $\mathrm{W}=$ Wall elements: 1 : surface only, different materials 2: glazed elements 3: with top light 4: with window 5 with door 6 : with door and top light $\mathrm{B}=$ Floor elements: 1: surface only, different materials, 2: heating or cooling elements 3 . with radiator 4 : with electric interface 5: with electric line 6: ventilation elements.

Figure 9. Catalogue of modular prefabricated building elements
The wall element W 6 determines the payload of the machine, which will be approximately $150 \mathrm{~kg}$.

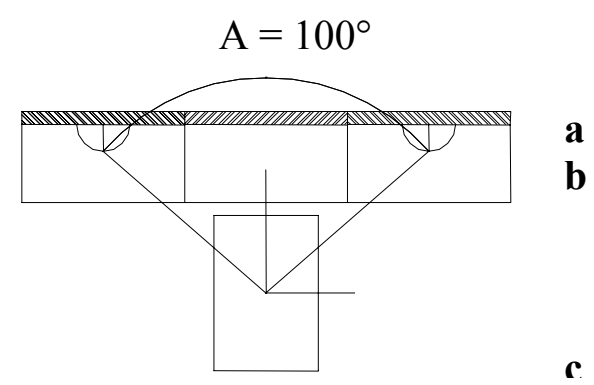

Legend:

A wall elements (H 3500, B 1250, T 100)

B ceiling or floor elements $(1250 / 600 \mathrm{~mm})$

C Assembly unit $\left(\mathrm{B}_{\max }=850 \mathrm{~mm}\right)$

Figure 10. Assembly unit in standard assembly dis-

b

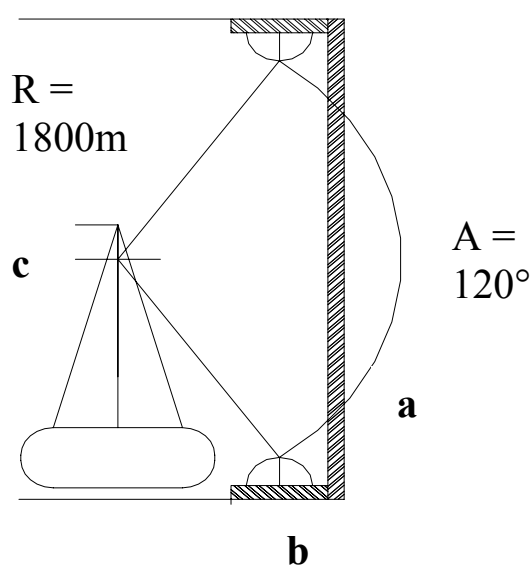

position, horizontal section

Legend:

A wall elements (H 3500, B 1250, T 100)

B ceiling or floor elements $(1250 / 600 \mathrm{~mm})$

C Assembly unit $\left(\mathrm{H}_{\max }=1900 \mathrm{~mm}\right)$

Figure 11. Assembly unit in standard assembly disposition, vertical section

Taking all calculations into account, the assembly unit has to fulfil the following basic requests:

Maximum total distributed load

(Carrier + processing module

+ gripper)

Maximum dimension (during driving modus) 
B $850 \mathrm{~mm}, \mathrm{~L} 1500 \mathrm{~mm}, \mathrm{H} 1900 \mathrm{~mm}$

Minimum Payload (incl. Gripper)

$150 \mathrm{~kg}$

Repeatability

Work envelope

horiz. R1650mm $>100^{\circ}$

vert. R $1800 \mathrm{~mm}$

$>120^{\circ}$

$30 \mathrm{~mm} / \mathrm{s}$

\section{CONCLUSIONS}

The simulation of an entire construction process with the new method, gave also information about time expenditure and the number and qualification of staff needed:

o The time of production and on-site construction could be reduced at least by $50 \%$ in comparison to the duration of a common project.

o Only one third of commonly needed staff is necessary with the new procedure. But it will demand increasing efforts in project planning, process planning and logistics.

o The staffs on site have to be more educated and specialized as usual.

In consequence the issue will be to reduce considerably unqualified and mostly non-ergonomic work on site and increase the number of highly qualified employees in human working conditions.

The new procedure could generate a higher quality of buildings and processes. Nowadays the chaos on site is proverbial and not only workers and contractors, but also the construction managers have to face a lot of sickening stress factors. The method of work by interior robots is able to obtain well-regulated structures and processes and therefore will achieve a better project outcome for all involved project partners.

\section{REFERENCES}

[1] Bock, Th., "Robot Oriented Design", Shokokusha, Tokio, May 1988.

[2] Bock, Th., Kreupl, K., Herbst, J. "Planning aids for enhancing the implementation of a mobile robot on the construction site", proceedings of the 17th International Symposium on Automation and Robotics in Construction, ISARC, September 2000.

[3] Dalacker, M. "Entwurf und Erprobung eines mobilen Roboters zur automatisierten Erstellung von Mauerwerk auf der Baustelle", Schriftenreihe Planung, Technologie, Management und Automatisierung im Bauwesen, Band 1, Fraunhofer IRB Verlag, Stuttgart, 1997.

[4] Feldmann, K., Koch, M. "Development of an Open and Modular Control System for Autonomous Mobile Building Robots with Flexible Manipulators", proceedings of the 17th International Symposium on Automation and Robotics in Construction, ISARC, September 2000. 